\title{
Is there a generational divide in environmental optimism?
}

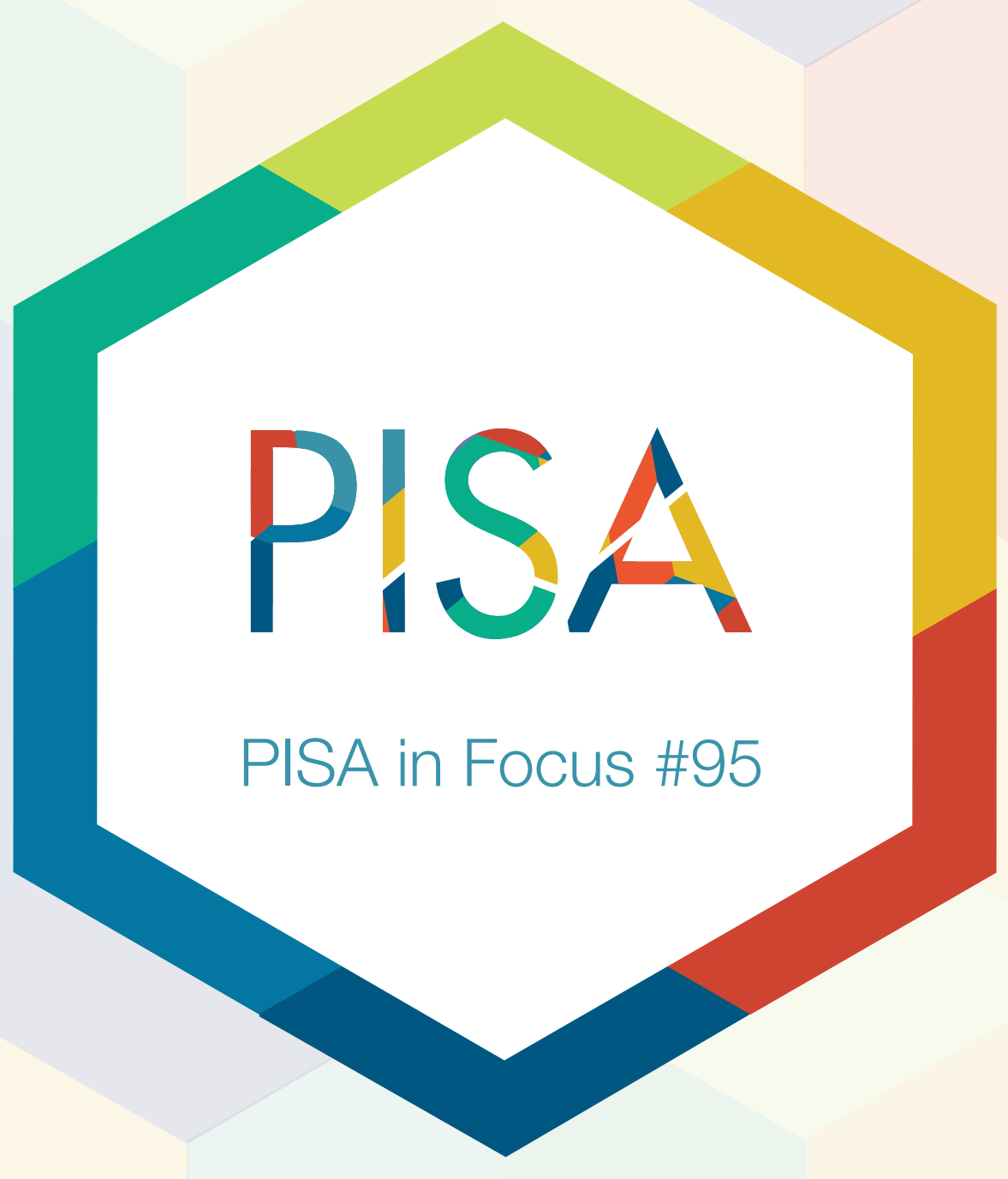




\section{Is there a generational divide in environmental optimism?}

- In 2015, only a minority of 15-year-old students believed that problems related to air pollution, the extinction of plants and animals, clearing forests for land use, water shortages and nuclear waste would improve over the next 20 years. In 12 of the 15 countries and economies that also asked parents about their beliefs, the parents' responses showed even greater pessimism about these environmental issues than their children's responses.

- Children of parents who held pessimistic beliefs about environmental issues tended to be somewhat more pessimistic than other children, while children of parents who held optimistic beliefs tended to be more optimistic. Boys and low-achieving students held more optimistic beliefs than girls and students performing at or above baseline levels of proficiency in science.

- On average across the 15 countries/economies that participated in this survey, students were most pessimistic about problems related to air pollution, while parents were most pessimistic about water shortages.

Problems associated with the environment loom large over the future well-being of young generations. A previous issue of PISA in Focus (PISA in Focus 87) shows that in 2015 many 15-year-old students believed that the future - their future was going to be worse, environmentally, than the present. In particular, only a minority of students (fewer than one in five, on average across OECD countries) believed that problems related to air pollution, the extinction of plants and animals, clearing forests for land use, water shortages and nuclear waste would improve over the next 20 years. But are teenagers more or less pessimistic than their parents?

\section{Fifteen-year-old students are, in general, more optimistic than their parents about environmental issues}

In 15 countries/economies that distributed the PISA parent questionnaire, it is possible to compare the environmental outlook of 15-year-olds to that of their mother or father (only one parent questionnaire was completed for each student). In all but three countries/economies, PISA data show that students were more optimistic than their parents about people's ability to solve problems related to five major environmental issues. In the Flemish Community of Belgium, students and parents were about equally pessimistic. In Hong Kong (China) and Macao (China), in contrast, students were more pessimistic than their parents about the environmental outlook over the following 20 years.

For example, in Croatia and Mexico, a majority of parents believed that all five problems would get worse, whereas a majority of students reported that at most four out of five problems would get worse. In Chile, France, Italy and Korea, more than $50 \%$ of parents reported that four or five (of five) problems would get worse, while a majority of students reported that at most three out of five problems would get worse. 


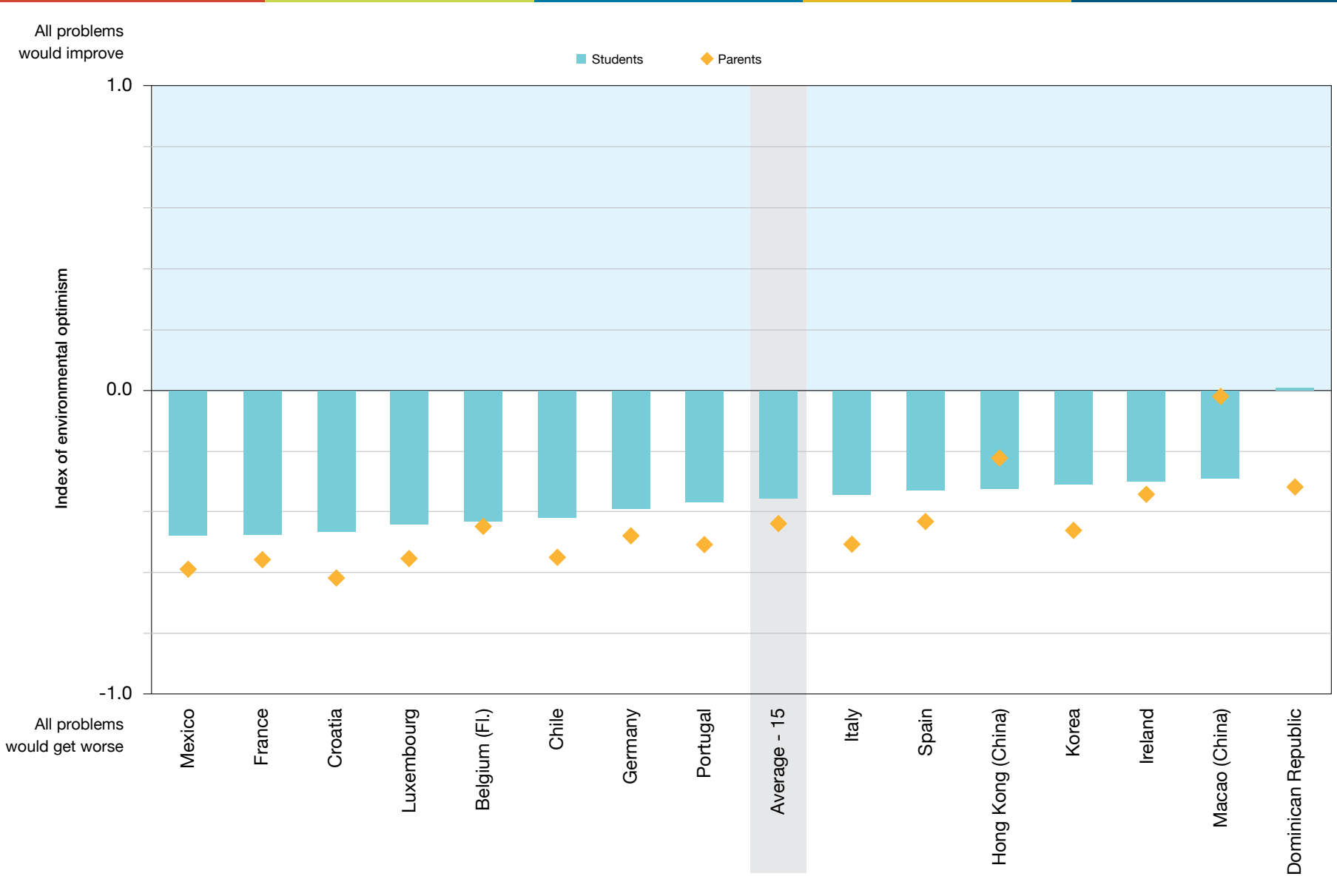

Countries and economies are ranked in ascending order of students' average index of environmental optimism.

Note: All differences between parents and students, except in the Flemish Community (Belgium), are statistically significant.

Source: PISA 2015 Database.

\section{How did PISA measure students' and parents' environmental outlook?}

Fifteen countries/economies participating in PISA surveyed both 15-year-olds and their parents or guardians about their outlook on five environmental problems - air pollution, the extinction of plants and animals, clearing forests for land use, water shortages and nuclear waste. Students and their parents reported whether they believed these problems would improve, stay about the same, or get worse.

This PISA in Focus reports analyses based only on students who answered at least three of these questions and whose parents did likewise. This represents different proportions of all PISA students in each country and economy participating in PISA. While response rates for students are generally high, in some countries/ economies, many students did not return the questionnaire intended for their parents. In particular, this sample represents more than $75 \%$ of the population of 15 -year-old students in Chile, Croatia, the Flemish Community of Belgium, France, Hong Kong (China), Ireland, Korea, Macao (China), Mexico and Portugal. Because less than $75 \%$ of the PISA population of 15 -year-old students is covered in Germany (35\%), Luxembourg (56\%), Spain (67\%), the Dominican Republic (70\%) and Italy (75\%), some results for these countries may not be nationally representative. 


\section{Girls are more pessimistic than boys, and high-achieving students more pessimistic than low-achievers}

Three characteristics were associated with more pessimistic beliefs amongst students.

First, students' beliefs were related to what their parents reported. This may reflect both that environmental values, like other values, are primarily transmitted from parents to children, and that children may influence their parents' beliefs and attitudes, a major assumption behind many school-based environmental education programmes. PISA data show that children of parents who held pessimistic beliefs tended to be more pessimistic about environmental issues than children of parents who held optimistic beliefs.

Next, in all 15 countries and economies, except the Dominican Republic, girls tended to be more pessimistic than boys about environmental issues; and in most countries, girls' level of environmental optimism in 2015 was closer to their parents' than boys' level of environmental optimism. In the Dominican Republic, Hong Kong (China), Macao (China) and Mexico, there was no significant difference between boys and girls in how close their beliefs were to those of their parents.

Finally, students with deeper knowledge and better skills in science also tended to be more pessimistic about environmental issues than low-achieving students. Students who performed below the baseline level of science achievement in the PISA test tended to report, on average, neutral beliefs about the future. In all countries and economies, students who performed at Level 3 or above - meaning that they can handle unfamiliar topics in science and identify the evidence supporting a scientific claim - tended to report significantly more pessimistic beliefs.

PISA data also show that the relationship between the beliefs of 15-year-olds and those of their parents was stronger amongst girls than amongst boys in 7 of the 15 countries/economies (Chile, the Flemish Community of Belgium, Ireland, Italy, Korea, Macao [China] and Portugal).

Students' and parents' beliefs, by gender and achievement

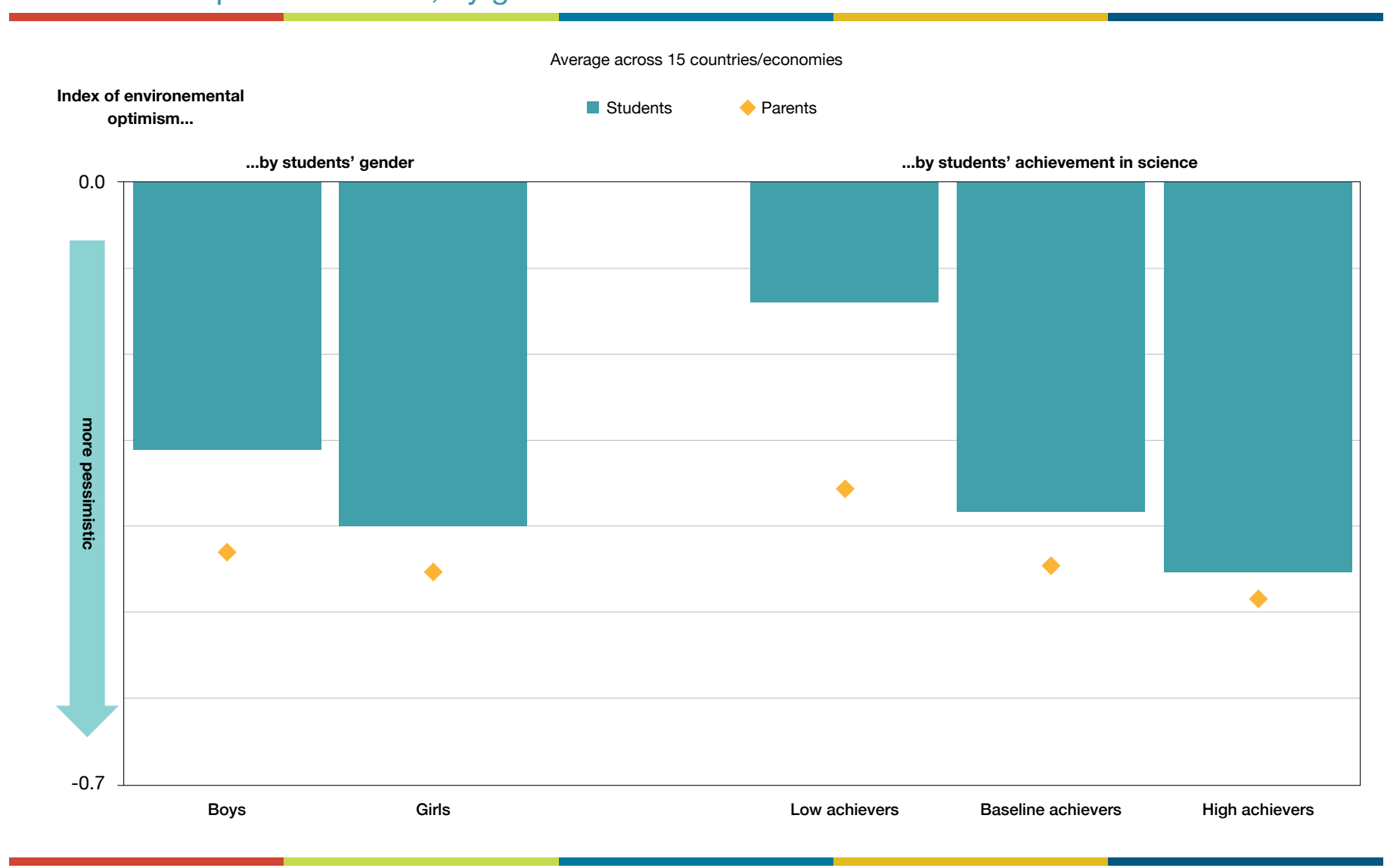

Source: PISA 2015 Database. 


\section{Teenagers tend to be more optimistic than their parents about issues related to water shortages and nuclear waste}

Of the five environmental issues considered, 15-year-olds were the least pessimistic, on average, about problems associated with water shortages and nuclear waste. In contrast, their parents were often as pessimistic about these two issues as about the remaining issues, resulting in large differences between parents' and children's beliefs regarding these two problems. In all countries and economies, except Hong Kong (China) and Macao (China), parents were more than 10 percentage points more likely than their children to be pessimistic about future water shortages. And parents in Croatia, the Dominican Republic, Germany, Italy, Korea, Luxembourg, Mexico and Portugal were also more than 10 percentage points more likely than their children to express concerns about nuclear waste.

What issues are 15-year-old students and their parents most pessimistic about?

Percentage of parents and students who believe that problems associated with environment issues will get worse over the next 20 year, by issue

- Students

$\triangle$ Parents
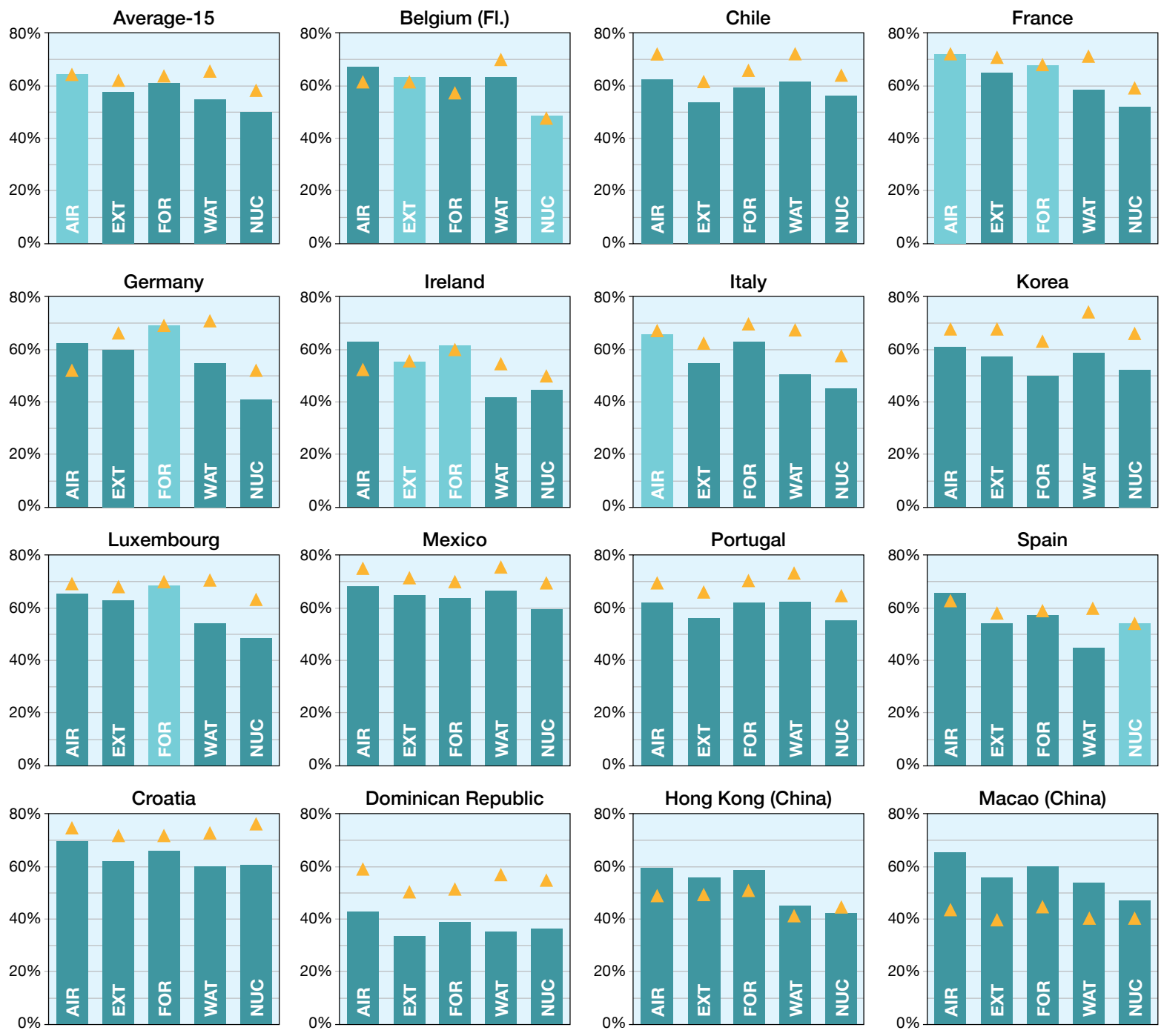

AIR: Air pollution; EXT: Extinction of plants and animals; FOR: Clearing of forests for land use; WAT: Water shortages; NUC: Nuclear waste. 
It is not possible to determine, based on PISA data, why the generation gap in beliefs about water shortages and nuclear waste observed in many countries is particularly wide. One possibility is that beliefs are strongly influenced by life experiences - and many parents of 15-year-olds, particularly in European countries, may have been affected as youth by the catastrophic Chernobyl nuclear accident that occurred in 1986. Another possibility is that teenagers are more optimistic than their parents about the use of science and engineering to solve environmental problems. While issues related to air pollution, the extinction of plants and animals, and clearing forests for land use require co-ordinated changes in the behaviour of a large number of people, new technologies and government action may go a long way towards solving problems related to nuclear waste and water management.

\section{The bottom line}

At any point in time, multiple generations of humans share the environment of planet Earth and thus a responsibility to preserve it for future generations. Today, however, teenagers and their parents are pessimistic about the future of our planet, and believe that many environmental problems will worsen over the coming decades. Educators should strive to ensure that realistic pessimism does not result in fatalism, but that better knowledge propels children - and their parents - into action, to help find or create the solutions to environmental problems requiring urgent attention.

\section{For more information}

Contact: Francesco Avvisati (Francesco.Avvisati@oecd.org)

See: Tables and technical notes about analyses in this PISA in Focus, available at:

www.oecd.org/pisa/pisaproducts/pisa-in-focus-all-editions.htm.

Echazarra, A. (2018), "Have 15-year-olds become "greener" over the years?", PISA in Focus, No. 87, OECD Publishing, Paris, https://doi.org/10.1787/6534cd38-en.

Coming next month: How are school-choice policies related to social diversity in schools?

This paper is published under the responsibility of the Secretary-General of the OECD. The opinions expressed and the arguments employed herein do not necessarily reflect the official views of OECD member countries.

This document, as well as any data and map included herein, are without prejudice to the status of or sovereignty over any territory, to the delimitation of international frontiers and boundaries and to the name of any territory, city or area.

This work is available under the Creative Commons Attribution-NonCommercial-ShareAlike 3.0 IGO (CC BY-NC-SA 3.0 IGO). For specific information regarding the scope and terms of the licence as well as possible commercial use of this work or the use of PISA data please consult Terms and Conditions on www.oecd.org. 